\title{
DOCTOR-PATIENT COMMUNICATION AND THE QUALITY OF CARE
}

\author{
JozIEN BENSING \\ Netherlands Institute for Prımary Health Care, P O Box 1568, 3500 BN Utrecht, The Netherlands
}

\begin{abstract}
In this article a companson is made between three independent sources of assessment of medical consultations A panel of 12 expenenced general practitioners rated 103 consultations with hypertensive patients on the quality of psychosocial care There was a wide consensus between the judges, resulting in a high reliability score Two contrasting groups were formed consultations that were rated high and those rated low in quality of psychosocial care A comparison was made between this general assessment of the quality of psychosocial care and a more detaled assessment of the same consultations on nine much used communication variables made by traned psychologists Knowledge about doctor-patient communication proved to predict very well as to which quality group the consultations belonged A very high percentage $(95 \%)$ was predicted accurately, solely on the basis of these nine communication variables Affectıve behaviour, and especially nonverbal affectıve behaviour had the strongest predictive power In the last part of the study a third source of asessment, $1 \mathrm{e}$ patients' satisfaction was compared with both other sources Much lower relationships were found, although most were in the predicted direction Affective behavior seems to be the most important in determining patıent's satisfaction The implications of these findings are discussed
\end{abstract}

\section{INTRODUCTION}

Since Michael Balint challenged the medical world with his statement "The Doctor is the Drug" [1], many researchers have found themselves in the unruly but nch and relevant research area of doctor-patient communication This has resulted in a steady flow of publications Generally speakıng, however, art of assessing the quality of physician communication is not well developed Information on communication skills is mostly derived from studies on patient knowledge, patients' compltance and patient satisfaction [2-4]* Whilst patients are a relevant source of information on certain aspects of care, Lebow [8] advises caution in the use of patient assessments since these do not correlate highly with what he calls 'objective', 1 e physician defined, measures of care, a result confirmed by DiMatteo and DiNicola [9] In this article we focus on (physician defined) quality of care In doing so we hope to meet the criticism "that the results of much research on doctor-patient communication have no face validity for clinicians and, consequently, are not readily used to change physician's behaviour in a desired direction" [5] As changes in the behaviour of physicians is the ultimate goal of our research program [10], it is relevant to explore the relationship between provider-defined quality of care and the concepts, used in this research program [10-13] If it were possible to identify a set of doctor-patient communication variables that have great powers of discrimlnation between consultations rated high in quality and those that are rated low in quality, this would indicate which types of behaviour should be tranned in medical education

* See for a review over this latter group of publications till 1983, Inu and Carter [5], and for a description respectively meta-analysis on 61 of these studies till ca 1986 Roter, Hall and Katz [6, 7]
In line with Dimatteo we have classified the quality of physicians conduct along three dimensions

1 a traditional technical dimension which involves technical knowledge, skill, etc

2 a nontraditional dimension which involves concern for psychosocial aspects of care

3 an 'art'-dimension which involves the interpersonal behaviour of the physician, his or her personal qualities and in general how the care is delivered [9].

Whilst not in any way underestımating the relevance of the other dimensions, we restrict ourselves in this article to the second the quality of psychosocial care Psychosocial care is an underdeveloped area that needs specific research effort It is puzzling that while on one hand there is a growing insight that psychological and social factors influence the development and severity of nearly every disease and the recovery and even survival of very many patients [14-16], on the other hand the implications of this knowledge are scarcely translated either into every-day practice, into medical education programs, or in the formulating of explicit criteria in quality assessment programs $[14,17,18]$ As Kerr White [14] stated in his fascinating report of the Wickenburg Conference,

In the face of this evidence we need to ask why medicinc has been so slow in acting to implement and increase this knowledge Why do we continue to behave as if it did not exist?

Psychosocial care is important in all medical practice, but especially in general practice not only in the detection and treatment of psychiatric, psychological and social problems but also (and perhaps even more because of the disguised influence of psychosocial factors) in most of the somatic problems that are presented in primary care the major killers as well as the self-hmiting diseases, the chronic conditions as 
well as (many) acute problems, clear diagnoses as well as undentified vague complaints

There is another reason for concentrating on the quality of psychosocial care Many concepts in doctor-patient communication research (e g 'affectuve behaviour' or 'empathy') originate from psychological theones (e g Roger's theory of 'unconditional positive regard' $[10,19]$ ) From this we hypothesize a strong relationship between the quality of psychosocial care and these communication variables

To stay in line with other publications in this field, and also to test the relevance of Lebow's caution in the use of patient assessments, we included a measure of patient satisfaction Many authors have argued that patients' assessment of the efficacy of their physicians' medical treatment (and hence their satisfaction) will be based on the perceived practitioners' affective behaviour (rather than on his instrumental behaviour) and on his attitude toward the patient as a human-being [20-25] From this we may hypothesize (despite Lebow's advice, but in line with some research findings [22-30]) a positive relationship between patient satisfaction on one hand and providerassessed quality of psychosocial care, respectively doctor's affective behaviour in doctor-patient communication, on the other

\section{RESEARCH QUESTIONS}

This leads us to two main research questions

1 Is it possible to develop a reliable measure of the 'quality of psychosocial care', and, if this is so

2 Is it possible to predict which consultations will be rated high-respectively low-on the quality of psychosocial care from ratıngs on certain aspects of doctor-patient communication (var)ables to be specified later on)? And what is the relation between quality of care, doctor-patient communication and patient satisfaction"

In this last research question we compare three kinds of assessment of the same consultation ( $F_{1 g} 1$ ) (a) the assessment of the quality of psychosocial care by experienced general practitioners (b) the assessment of doctor-patient communication by trained psychologists, and (c) the assessment of the consultation and the GP in general by the patient himself This procedure can be considered as a mutual crossvalidation of the three measures
Study I Assessing the Quality of Psychosoctal Care

\section{Methods}

Selections of the consultations To assess the quality of care we used video recordings of real doctorpatient consultations These are considered to produce the most valuable information for assessing the quality of care in general practice $[2,5,31]$ and especially the quality of psychosocial care, because these video recordings enable us to assess nonverbal as well as verbal behaviour [5] We selected the consultations for this study from videotaped doctor-patient consultations we had collected and observed in previous research projects $[12,13]$ These observations have been computerized to enable further analyses, besides, the tapes are ready for new observations (see for more information about this collection of video recordings Bensing, 1983 [32])

Carter and Inu [5] concluded that the heterogeneity of consultations is one of the big problems facing current physician-patient interaction research That is why we decided to select consultations which had a common diagnosis We preferred a diagnosis with a high medical relevance level We looked for the kind of problem that evidently includes both medical and psychosocial aspects In order to be able to do the necessary statistical analyses, it had to be a diagnosis with a high frequency level in general practice

Hypertension (and other blood pressure problems) proved to meet all these requirements The medical relevance of blood pressure problems is unchallenged, as hypertension is a known risk factor for cardiovascular diseases mortal enemy number one It is generally considered to be serious by general practitioners Hypertension also appears to be a condition in which both medical and psychosocial aspects are considered to be relevant by general practitioners Grol [33], Verhaak [34] and, in a slightly different way, Link et al [35] made use of this characteristic of the problem 'hypertension' by using 'hypertension' as an item in a rating scale to measure the so-called 'psychosocial onentation' of a general practitioner That fact that patients are aware of the psychosocial aspects of hypertension too, was illustrated by a nationwide research project run by the Netherlands Consumer Association [36], results which are in line with a survey conducted in 1973 by the National Institute of Mental Health in the US A [37]

A general look in the vast collection of literature on 'hypertension' shows us remarkable differences in the

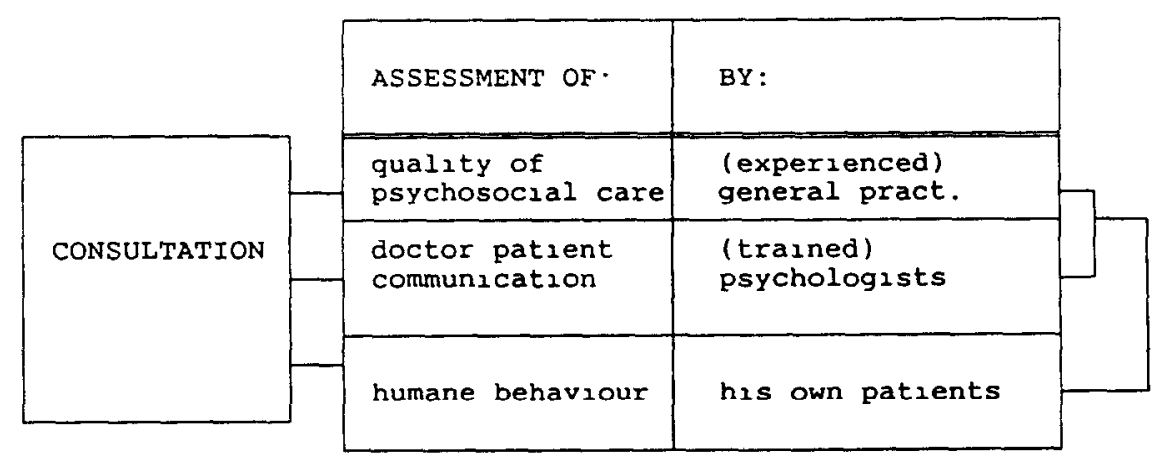

Fig 1 Research design 
Table 1 Age-sex distribution of patients with hypertension or other blood pressure problems in videotaped consultations, compared with figures from the Britush Second National Morbidity Survey [28]

\begin{tabular}{lcccc}
\hline & \multicolumn{4}{c}{ Sex } \\
\cline { 2 - 5 } Age & Man & Woman & Total & Total NMS \\
\hline$<45$ & 11 & 10 & $21(20 \%)$ & $(10 \%)$ \\
$45-64$ & 10 & 23 & $33(42 \%)$ & $(47 \%)$ \\
$65-74$ & 11 & 14 & $25(24 \%)$ & $(29 \%)$ \\
$\geqslant 75$ & 3 & 11 & $24(14 \%)$ & $(14 \%)$ \\
Total & 35 & 68 & 103 & $(100 \%)$ \\
& $(34 \%)$ & $(66 \%)$ & $(100 \%)$ & \\
NMS & $(35 \%)$ & $(65 \%)$ & $(100 \%)$ & \\
\hline
\end{tabular}

amount of attention paid to the psychosocial aspects of this condition In the epidemiological literature there is a widespread acceptance of the influence of social and psychological factors [38-40], even of the evident influence of a wrong diagnosis 'hypertension' on the mental state of $a$ prior healthy people $[36,41]$ But in the literature about the (medical education of) the treatment of hypertension, there is a remarkable lack of attention to the growing body of knowledge that shows that the onset, severity, and treatment of hypertension is influenced by psychosocial factors A striking example of this is given to us by Dove's review of sets of explicit criteria for the diagnostic work-up of hypertension (cited by Donabedian, 1982) more than 60 criteria have been formulated by different groups of physicians, and not one of these criteria has to do with psychosocial factors [18]' Hypertension proves to be an eminent example of Kerr White's lamentation, "Why do we continue to behave as if this knowledge did not exist" [14] Hypertension seems to be a suitable case for treatment in this research project

From one file in our video store $(n=1569)$, we selected all the consultations involving hypertension or other blood pressure problems (ICPC-codes K85-K87) We found 103 consultations that met the ngourous demands of technical quality $(66 \%)$ This figure is to be expected from a random sample of consultations in general practice [42] The age-sex distribution of the patients is given in Table 1 and is much similar to distributions found in morbidity research in general practice [43] These 103 consultations have been used in this article

Procedures Twelve general practitioners (further to be called 'judges') were asked to rate the selected consultations $(n=103)$ The judges were all experienced general practitioners with a minimum of 5 years in practice Their ages varied from 30 to 70 Four of them were women They had no knowledge of the previous observation sessions

The judges were given a set of written instructions about how to assess the different dimensions of the quality of care (medical-technical, psychosocial and the management of the doctor-patient relationship) 'Psychosocial care' was defined as 'receptıveness for and treatment of the (aetiological and consequential) non-somatic aspects of the presented health problem'. In their assessment of the quality of psychosocral care the judges were asked to give one general judgment on the total consultation, considenng the GP's

- sensitivity to the patients' verbal and nonverbal cues that may hint at non-somatic aspects of the health problem
- active explorations of the patients' possible psychosocial problems

- informativeness about the relationship between psychosocial problems and physical sensations or manifestations

- type of counselling, passive (supporting, comforting, reassuring) or active (intention to insight-promotion or behavioral change)

- undue attention to psychosocial aspects (too much or uni-directional attention can be as bad as too hittle')

As with Dutch school marks, their ratings could vary between 0 and 10

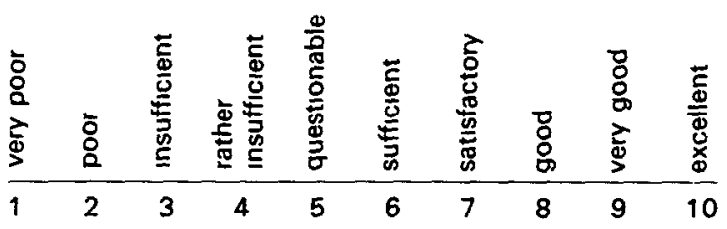

The judges got a short training-program to become familar with the method and the concepts used In order to avoid their mutually influencing one another, the judges worked individually To avoid bias from earlier ratings, consultations involving the same doctor (there were 27 different GP's on the video) were spread over the videotapes One of the researchers was always at hand to answer questions Sometımes it happened that a judge knew a particular general practitioner on the video To avoid bias, he did not rate these consultations

\section{Results}

The assessment procedure proved to be feasible; the judges had no apparent difficulties in assessing the videotaped consultations in conformance with our instructions The scale showed a good range of ratings all the judges used 6 to 9 values of the 10-point scale The judges were not afraid to give low ratings as well as high ratings The average mean of the total group is 60 , with individual means ranging from 53 to 81

In Table 2 the correlations between the 12 judges are given Most of the correlations (92\%) are significant. Moreover the interassessor-reliability, measured by Cronbach's Alpha, is high 088 Cronbach's alpha did not nse when any of the judges was excluded from the analysis So, it is possible to use the mean as a psychosocial quality measure However, interassessor reliability is just one and perhaps not the most important condition to develop an adequate instrument for quality of care Another condition is intercase reliability, which means that a high score on one consultation of a GP goes along with a high score on other consultations of this same GP We performed an intercase reliability-test on those doctors from our file who had 5 or more videotaped consultations. The results of these analyses for doctors are presented in Table 3

The reliability figures are high with an average Cronbach's alpha of 083 A oneway analysis of variance shows larger differences between GP's than within $(F=1267 ; P<00001)$ These results give additional weight to the instrument and warrant its use as a psychosocial quality measure 
Table 2 Correlation matrix of the ratings of 12 independent judges

\begin{tabular}{|c|c|c|c|c|c|c|c|c|c|c|c|}
\hline \multicolumn{12}{|l|}{ judge 1} \\
\hline judge 2 & $032^{\circ}$ & & & & & & & & & & \\
\hline judge 3 & $026+$ & $049^{\circ}$ & & & & & & & & & \\
\hline judge 4 & $044^{*}$ & $035^{*}$ & $032^{*}$ & & & & & & & & \\
\hline judge 5 & $030^{\circ}$ & $050^{\circ}$ & $045^{\circ}$ & $031+$ & & & & & & & \\
\hline judge 6 & $047^{*}$ & $050^{*}$ & $050^{\circ}$ & $043^{*}$ & $053^{*}$ & & & & & & \\
\hline judge 7 & $050^{*}$ & $041^{*}$ & $046^{*}$ & $037^{*}$ & $046^{*}$ & $072^{*}$ & & & & & \\
\hline judge 8 & $044^{*}$ & 015 & $040^{*}$ & $040^{*}$ & $030+$ & $055^{*}$ & $062^{*}$ & & & & \\
\hline judge 9 & $040^{*}$ & $026 t$ & $049^{*}$ & $050^{*}$ & 015 & $049^{*}$ & $042^{*}$ & $034^{*}$ & & & \\
\hline judge 10 & $045^{*}$ & $031+$ & $030+$ & $041^{*}$ & $029+$ & $052^{*}$ & $055^{*}$ & $042^{*}$ & $038^{*}$ & & \\
\hline judge ll & 017 & $035^{*}$ & $040^{\circ}$ & $031^{*}$ & 022 & $036^{*}$ & $053^{*}$ & 023 & $032^{*}$ & $028 \dagger$ & \\
\hline \multirow[t]{2}{*}{ judge 12} & $060^{*}$ & $028 t$ & $039^{*}$ & $047^{\circ}$ & $045^{*}$ & $064^{*}$ & $065^{*}$ & $056^{*}$ & $034^{*}$ & $038^{*}$ & $039 *$ \\
\hline & 1 & 2 & 3 & 4 & 5 & 6 & 7 & 8 & 9 & 10 & 11 \\
\hline
\end{tabular}

One-tailed significance $+P \leqslant 001,{ }^{*} P \leqslant 0001$

Minimum pairwise $n$ of cases $=74$

Figure 2 shows the distribution of the ratings on this quality measure The lowest rating is 33 , the highest 80 The mean is 62 , the median 63 The standard deviation is 096 The distribution has a slight positive skewness, but is a reasonable approximation of a normal distribution In the second study the ratings on this quality measure are used in the analyses When it was necessary for some spectic analyses to compare contrast-groups, all consultatıons with ratıngs 'questionable' or less $(<59)$ were grouped-as in Dutch classrooms--in the 'negative' category ( $n=36$, this is $35 \%$ of all consultations), in the same way all consultations with ratungs 'satisfactory' or more $(>70)$ were classified as 'positive' ( $n=25$, this is $24 \%$ of all consultations)

Study II Doctor-Patient Communtcation, Pattent Satisfaction and the Qualty of Care

\section{Methods}

Doctor-patlent communication For the data on doctor-patient communication we made use of the data-collection and observations of a previous study carried out by our research group The methods and reliability figures have been published elsewhere $[12,13,34]$ Note that these observations of doctorpatient communication were done by psychologists, whilst the quality assessment in the first part of this study was done by general practitioners (and at a different tıme) There is no contamination in the observation of the independent and dependent var1ables in this study

Three groups of doctor-patient communication variables have been used

I Affective behaviour The concept "affective behaviour' (which includes attentive, listening, emphatic behaviour and the ability of the physician to

\begin{tabular}{lc}
$\begin{array}{c}\text { Table } 3 \\
\text { with } 5 \text { or more consultations }\end{array}$ \\
\hline Number & $\begin{array}{c}\text { Cronbach's } \\
\text { diphd }\end{array}$ \\
\hline Doctor 411 & 081 \\
Doctor 415 & 085 \\
Doctor 416 & 087 \\
Doctor 419 & 091 \\
Doctor 420 & 066 \\
Doctor 423 & 085 \\
Doctor 426 & 077 \\
Doctor 427 & 090 \\
Average & 083 \\
\hline
\end{tabular}

communicate concern, warmth and interest in the patient as a whole person) onginates from psychological theories, especially the Rogenian theory of 'unconditional positive regard' [44] but has since long made its introduction into the medical world (with Balınt [1] as its famous pioneer) Now it is by far the most popular concept in doctor-patient communication research [3-7] To summanze the major findings, affective behaviour proves to be related to patients' compliance $[20,21,26,45,46]$ and patients' satısfaction $[22,23,25-30]$ It seems also to be related to the doctor's ability to detect psychiatric illness [13,47-49] Gask et al [47] found an increase in affective behaviour after a training course to improve psychiatric interviewing styles, together with a signifcant improvement in the trainee's ability to identify psychiatric illness accurately

In this study affective behaviour has been operationalized in four vanables (for more detalls see Refs $[12,13,34])$

1 shown interest (5-point scale)

2 nonverbal attention (proportion of time GP looks at patient)

3 encouraging (utterances $/ \mathrm{min}$ )

4 verbal empathy (utterances/min)

2 Systematic and purposive behaviour This group of variables is derived from a popular 'school' among Dutch general practitioners, called 'the methodical approach' (developed by the Netherlands College of General Practitioners, see for an overview of this development since 1976 Sluys and van der Leden [50] It refers to the active dimension in the GP's behaviour From our own previous research we learned that a passive, empathic attitude is perhaps a necessary, but not always a sufficient condition to elicit information from the patient about more per-

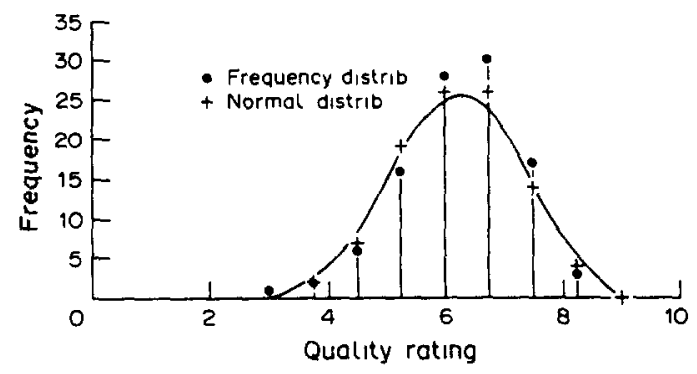

Fig 2 Frequency distribution of the psychosocial quality ratings 
sonal or emotional topics $[10,11]$, a view that is shared by others engaged in interview-training in primary care [47] By active interventions (for instance the introduction of new topics) the general practitioner can show his willingness to discuss psychosocial aspects of the presented problem This is all the more important in general practice where patients are not always conscious of the multifaceted nature of their problems, and not always sure of their doctor's interest in non-somatic matters Knowing that patients do not always present their main problems on the first occasion, the general practitioner should ask himself with every new patient 'Why has this patient come to me with this specific problem at this specific moment in time?" Clarifying the reason for the encounter is one important feature of 'systematic and purposive behaviour', the systematic structuring of the consultation if more than one problem is presented, another To sum up, the vanables in this subgroup are the following

1 clanfying (proportion of complaints for which the reason for encounter is discussed)

2 structuring (proportion of consultations with a structured approach)

3 purposive probing (introduction of new topics)

3 Patsent-centered behaviour Since Byrne and Long published their classical 'Doctors talkıng to patients' [57], there has been a growing interest among researchers in doctor-patient communication in terms of one of their main concepts, patientcentered behaviour (as opposed to doctor-patient behaviour) Byrne and Long introduced the so-called power-shift model in general practice, and especially when non-somatic aspects are part of the problem, it is necessary to use the knowledge of the patient (himself an expert on his own feelings) in understanding the origin of the problem and trying to find possible ways of solving it Barsky et al [52] also fomulated several reasons for a patient-centered structure for the medical interview in primary health care they state that the interview itself involves negotiation and consensus seekıng, rather than interrogation, inquisition and prescribing Speedling et al [53] follow a similar line of reasoning in their plea for a yardstick that goes beyond the one dimensional concept of the 'friendly physician' They state that for a consultation to be effective the patient has to get involved in medical decision-making which may involve a great deal of hard work and include periods of conflict and need for compromise' Trying to involve the patient in medical decision-making is the more important in primary care, where the physician manages symptoms and disability as much as he cures biological diseases, and were it is the patient himself who actually has to carry out the plan of management and treatment Following Byrne and Long [51], we use a 5-point scale to measure the degree of influence the patient gets in a consultation And like them we make a distinction between the diagnostic phase and the therapeutic phase The operationalisations are

1 patient-centered behaviour in the diagnostic phase (5-points scale)

2 patient-centered behaviour in the therapeutic phase (5-points scale)
Pattent satisfaction For the data on patient sattsfaction we also make use of previous work At the time of the video-recordings, immediately after the consultation, the patients were asked to fill in a questionnaire with a Patient Satisfaction Scale This scale was developed by Verhaak [34], it is a shortened and slightly modified version of the patient satisfacthon scale of Cassee [54], a much used scale in the Netherlands The scale consists of a questionnaire with 6 items of a five-point Likert ratıng format (see Appendix) The items are similar to items used in other patient satisfaction questionnaires [53-60] They reflect Ware's dimension of 'humaneness' $[59,60]$, or what other authors described as 'affective satisfaction' [56] or 'evaluation of expressivity' [57]

The scale has a moderate reliability of 072 (Cronbach's alpha) The scale has one clear dimension a factor analysis showed one factor with an Eigenvalue of 27 and $46 \%$ explained variance The factorscores are further used in this study

\section{Results}

We want firstly to link the quality of psychosocial care with different aspects of doctor-patient communication To be more specific we want to know if and to what extent certain much used variables in research on doctor-patient communication can predict whether a consultation will be rated high or low in terms of the quality of psychosocial carc Thereafter, we will examine the interrelationships between the quality of care, doctor-patient communication and patient satisfaction, therewith linkıng the results of this study with others from the literature

In Table 4 , the mean and standard deviation are given of the communication variables for the consultations that have positive, respectively negatıve ratings for the quality of psychosocial care The differences between the two subgroups (measured by the $t$-test) are given in the last column We see that there are significant differences between the positively and negatively rated consultations for all the var1ables of the subgroup 'affective behaviour' and all the variables of the subgroup "patient-centered behaviour' This means that in positively rated consultations, the general practitioner shows more interest in the patient, has more eye-contact, shows more empathy (by reflecting upon the words of the patient or paraphrasıng what he says), and encourages hım more by semiverbal nonspecific utterances (hike hm$\mathrm{hm}$, ah etc ) In these consultations he is also more patıent-centered, whereas in the negatively rated consultations he is more doctor-centered This applies both to the diagnostic and the therapeutic phase The variables from the subgroup 'systematic and purposive behaviour' do not yield significant differences between the two subgroups

A discriminant analysis was performed in order to get a better understanding of the independent contribution of the nine communication variables to the discrimination between positively and negatively assessed consultatıons (see Table 5)

An impressively high percentage of the consultations $(95 \%)$ can be predicted correctly as belonging to the positively-respectively negatively-rated, group of consultations A stepwise variable selection shows that 'nonverbal attention', that is the amount 
Table 4 Communication variables in consultations with a high, respectively low psychosocial quality assessment

\begin{tabular}{|c|c|c|c|c|c|c|}
\hline \multirow[b]{2}{*}{ Vanable } & \multicolumn{2}{|c|}{ Posituve } & \multicolumn{2}{|c|}{ Negatıve } & \multicolumn{2}{|c|}{ Difference } \\
\hline & $x$ & (SD) & $x$ & (SD) & $t$ & $P$ \\
\hline $\begin{array}{l}\text { Affective behaviour } \\
\text { interest } \\
\text { nonverbal attention } \\
\text { encouraging } \\
\text { verbal empathy }\end{array}$ & $\begin{array}{l}40 \\
063 \\
39 \\
059\end{array}$ & $\begin{array}{l}\left(\begin{array}{ll}0 & 7\end{array}\right) \\
\left(\begin{array}{ll}0 & 2\end{array}\right) \\
\left(\begin{array}{ll}2 & 2\end{array}\right) \\
\left(\begin{array}{ll}0 & 58\end{array}\right)\end{array}$ & $\begin{array}{l}29 \\
027 \\
19 \\
014\end{array}$ & $\begin{array}{l}\left(\begin{array}{ll}0 & 7\end{array}\right) \\
\left(\begin{array}{ll}0 & 2\end{array}\right) \\
\left(\begin{array}{ll}1 & 2\end{array}\right) \\
\left(\begin{array}{ll}0 & 19\end{array}\right)\end{array}$ & $\begin{array}{l}648 \\
812 \\
427 \\
385\end{array}$ & $\begin{array}{l}<0000 \\
<0000 \\
<0000 \\
<0001\end{array}$ \\
\hline $\begin{array}{l}\text { Purposive structuring } \\
\text { clanfyıng } \\
\text { structunng } \\
\text { purposive probing }\end{array}$ & $\begin{array}{l}12 \\
25 \\
15\end{array}$ & 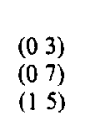 & $\begin{array}{ll}1 & 3 \\
2 & 4 \\
1 & 1\end{array}$ & $\begin{array}{l}\left(\begin{array}{ll}0 & 4\end{array}\right) \\
\left(\begin{array}{ll}0 & 8\end{array}\right) \\
\left(\begin{array}{ll}1 & 1\end{array}\right)\end{array}$ & $\begin{array}{r}-047 \\
-015 \\
123\end{array}$ & $\begin{array}{l}\mathrm{ns} \\
\mathrm{ns} \\
\mathrm{ns}\end{array}$ \\
\hline $\begin{array}{l}\text { Patient-centered behaviour } \\
\text { diagnostic phase } \\
\text { therapeutic phase }\end{array}$ & $\begin{array}{l}34 \\
30\end{array}$ & $\begin{array}{l}\left(\begin{array}{ll}0 & 9\end{array}\right) \\
(099)\end{array}$ & $\begin{array}{l}24 \\
23\end{array}$ & 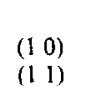 & $\begin{array}{l}385 \\
276\end{array}$ & $\begin{array}{l}<0000 \\
<0008\end{array}$ \\
\hline Total & & $n=41$ & & $n=32$ & & \\
\hline
\end{tabular}

of eye-contact, has the strongest predictive power, followed by 'shown interest' (also nonverbal) Other variables that have a significant independent influence $(P<0000)$ on the chance of a consultation being rated positively or negatively by independent judges are patient-centeredness in the diagnostic phase', 'verbal empathy', 'clarifying' and 'purposıve probing' Summarizing the results, we may conclude that the judges let themselves be guided in their rating of the quality of psychosocial care mainly by the 'affective behaviour' of the GP in question (and especially the nonverbal affective behaviour shown interest and,eye-contact), and-somewhat less-by the more verbal (and active) ways a GP tries to get patient's involvement in the consultation by clarifying the reasons for encounter, purposive probing and giving the patient influence in the diagnostic phase of the interview

In the last part of this study we want to examine the relationship between the ratings of the judges on the quality of psychosocial care, the communication variables and the expressed satisfaction of the patient As stated before, we hypothesize a positive relationship between the satisfaction of the patient and the ratings of a panel of independent general practitioners We also hypothesize a positive relationship between the satisfaction of the patient and the communication variables of this study, this hypothesis is enforced by the fact that these communication variables prove to be highly related to the ratings of the

Table 5 Stepwise discriminant analysis and classification table with quality as dependent and 9 communication variables as independent variables

\begin{tabular}{clcc}
\hline Step & \multicolumn{1}{c}{ Entered } & Wilk s lambda & Signıficance \\
\hline 1 & Nonverbal dtention & 0558 & 0000 \\
2 & Interest & 0384 & 0000 \\
3 & Pdient-centered behdviour & & \\
& in diagnostic phdse & 0334 & 0000 \\
4 & Verbal empathy & 0296 & 0000 \\
5 & Clarifying & 0274 & 0000 \\
6 & Purposive probing & 0267 & 0000 \\
\hline
\end{tabular}

$95 \%$ Correct classifications

1 canoncal discriminant function with an EIGEN value of 275

\begin{tabular}{lccc}
\hline & & \multicolumn{2}{c}{ Predicted group membership } \\
\cline { 4 - 4 } Actual group & $(n)$ & High quality & Low quality \\
\hline High quality & $(26)$ & $25(96 \%)$ & $1(4 \%)$ \\
Low quality & $(36)$ & $2(6 \%)$ & $34(94 \%)$ \\
Total & $(62)$ & 27 & 35 \\
\hline
\end{tabular}

panel judges In Table 6 the results are presented In the first column the correlations are presented between patients' satisfaction on one hand, and the panel's assessment of psychosocial quality, respectively the observed doctor-patient communication on the other In the second column the correlations are presented between the panel's assessment of psychosocial quality on one hand and the observed doctor-paticnt communication on the other to make a comparison possible of the relative contribution of the different sources

Patient's satisfaction on the 'humaneness' or 'the affective aspects' of the consultation has a barely significant $(P=0045)$ and not very high $(019)$ correlation with the panel-assessed quality of psychosocial care Of the communication variables three variables have a slight relationship $(P=005)$ with patients' satisfaction 'shown interest', 'verbal empathy' and 'purposive probing' The other correlations are low to very low A discriminant analysis with patients' satısfaction as dependent and the nine communication variables as independent variables (analogue to the discriminant analysis of the quality rating, described above) showed $77 \%$ correct predictions (see Table 7), which 15 only $27 \%$ more than chance (with two groups about $50 \%$ of the consultations would have been predicted correctly by chance) The variables with an independent (albeit small) influence on patients' satisfaction were (in this order)

$$
\begin{aligned}
& 1 \text { nonverbal attention } \\
& 2 \text { verbal empathy } \\
& 3 \text { encouraging } \\
& 4 \text { purposive probing }
\end{aligned}
$$

\section{CONCLUSION AND DISCUSSION}

This study has produced some interesting results First, it proved to be possible to develop a reliable instrument for the assessment of the quality of psychosocial care (interassessor alpha $=088$, average intercase alpha $=083$ ), using a method that is primarly based on implicit criteria the judges were not asked to score explicit criteria, but to weigh up the different aspects of psychosocial care (according to a written definition and operationalization) into one final judgment, thereby following Donabedian's advice "for the asessment of those cases that do not 
Table 6 Correlation matrix of patients' satufaction, physicians' quality ratung and observed doutor-patient cornmunication

\begin{tabular}{|c|c|c|}
\hline & $\begin{array}{l}\text { Factorscore on the } \\
\text { patient satisfaction } \\
\text { scale }\end{array}$ & $\begin{array}{l}\text { Quality ratung } \\
\text { independent judges }\end{array}$ \\
\hline $\begin{array}{l}\text { Quailty ratıng of independent } \\
\text { judges (GP's) }\end{array}$ & $019+$ & \\
\hline $\begin{array}{l}\text { Assessment of } \\
\text { doctor-patient } \\
\text { communication }\end{array}$ & & \\
\hline $\begin{array}{l}\text { Affective behaviour } \\
\text { Interest } \\
\text { Nonverbal attention } \\
\text { Encouraging } \\
\text { Verbal empathy }\end{array}$ & $\begin{array}{l}025 \dagger \\
006 \\
003 \\
024 \dagger\end{array}$ & $\begin{array}{l}060^{* *} \\
066^{* *} \\
042^{* *} \\
039 \dagger\end{array}$ \\
\hline $\begin{array}{l}\text { Purposwe structuring } \\
\text { Clanfying } \\
\text { Structuring } \\
\text { Probing }\end{array}$ & $\begin{array}{rl}0 & 00 \\
-0 & 02 \\
023 \dagger\end{array}$ & $\begin{array}{l}003 \\
004 \\
016^{*}\end{array}$ \\
\hline $\begin{array}{l}\text { Patient-centered behavour } \\
\text { Diagnostic phase } \\
\text { Therapeutic phase }\end{array}$ & $\begin{array}{ll}0 & 12 \\
0 & 04\end{array}$ & $\begin{array}{l}039^{* *} \\
030^{* * *}\end{array}$ \\
\hline
\end{tabular}

conform to the more strictly medical criteria" [18] In the discussion about the relative merits of assessment procedures using implicit criteria versus those using explicit critena, the supposed low reliability of the former is considered to be a major reason for refraining from quality assessment based on implicit critena This is a serious problem for researchers in primary health care (as well as those engaged in medical education in this field), as explicit criteria are seldom completely satisfactory for the assessment of consultations that do not conform to the more strictly medical critena-which is very common in primary health care In this light the relatively high reliability figures in our study come as a welcome surprise However, the high reliability of the used procedure in our study is probably caused by the size of our panel $(n=12)$, which proved to be large enough to cancel out random fluctuations Caution is still needed when using smaller sized panels and with this study we certainly do not want to open the door for 'singlehanded' implicit quality assessments, as often is done in medical-education literature, where one- or twopeople panels are no exception

The reliability tests showed another interesting result the intercase reliability proved to be high, which means that a high score on one consultation of a GP goes along with a high scorc on other consultations of this same GP As we have spread the consultations of the GP's over the videotapes to munumize the so-called 'Halo-effect' on the judges, we can assume that 'quality of psychosocial care' is a doctor's characteristic as well as a consultation's characteristic This means that observing about five consultations of a certain GP handling patients with

Table 7 Stepwise discriminant dnalysis with patients' satısfaction as dependent and 9 communication variables as independent variables

\begin{tabular}{clcc}
\hline Step & \multicolumn{1}{c}{ Entered } & Wilk's lambda & Significance \\
\hline 1 & Nonverbal attention & 087 & 0028 \\
2 & Verbal empathy & 078 & 0014 \\
3 & Encouraging & 064 & 0002 \\
4 & Probing & 054 & 0000 \\
\hline
\end{tabular}

$77 \%$ correct classifications

I canonical discriminant function with an EIGEN value of 0850 the same health problem (in this case hypertension) can give a fairly good impression about his general performance with these patients

Having found a satisfactory answer to the reliability-question, we now want to turn to the always much more complicated question of the validity of our measures The limitations of this study just make it possible to draw conclusions about concurrent validity, no predictive validity can be assessed as we have no actual measure of the quality of care, such as outcome of treatment or health and functional status of the patient Nevertheless, within these limitations some interesting results can be reported We found a remarkable powerful relatıonship ( $95 \%$ correct predictions in a discriminant analysis) between the panel's psychosocial quality assessment on the one hand, and a set of much used communication variables on the other Therewith the study certainly establishes what it is that experienced general practitioners view as quality visits Appreciating the consistency with which these criteria are applied (as reflected by the correlations among judges) it can be argued that the quality ratings are a reflection of common conceptions and norms of practice among physicians, and thus build a good case for the (face) validity of the communication skills under study, particularly 'affective behaviour' and 'patient-centered behaviour' As a result, this study provides us with indications as to what types of behaviour are useful for training purposes in medical and postgraduate education Gask et al [47,48], Hornsby et al [61] and Bensing et al [10] demonstrated the possibility to train such behaviour and to evaluate the effects of such a training program

The results of this study particularly enforce the relevance of 'affective behaviour' for an adequate medical interview, as many authors have stressed before $[7,20-30,46-50,61]$, but contradict the research results of other authors [62-65] who doubt this major influence For that matter, the results can also shed some light upon a possible explanation for these contradictory findings in literature, for we found that especially the nonverbal aspects of affective behaviour (eye-contact and shown interest) had a strong predic- 
tive power on the quality rating of psychosocial care. The researchers that press the importance of more instrumental types of behaviour (e g. 'task-oriented' behaviour) over 'socioemotional' behaviour-the later being more or less comparable with our concept of 'affective behaviour'), like Roter et al [64] and Wolraich et al [63] use audiotapes as observation instruments and only code verbal behaviour In these studies the nonverbal aspects of affective behaviour are necessarily neglected It seems wise to maintain a distınction between the verbal and the nonverbal aspects of affectıve behaviour and, as Inus and Carter have stated [5] "to complement systems that categor1ze and analyze a single type of interaction (e $\mathrm{g}$ verbal statements only) by other analytic approaches, to capture and characterize other means of communication (e $\mathrm{g}$ gesture and nonverbal communication)" The present controversies in literature on this point could possibly be resolved, if the much used observation protocols of Bales, Roter or Stiles, that completely rely on verbal behaviour, would be enlarged with nonverbal measures This links up with a pivotal statement made by Davis [66], in which she states that most doctors know how to talk in a warm and friendly way, without being really patient-centered or really interested in the patients' problems or wishes. She stresses that it is much easier to control your verbal behaviour than your nonverbal behaviour More research is necessary, but this study again stresses the relevance of nonverbal behaviour, also in determinıng patient satisfaction ${ }^{\prime}$

Another point worth discussion, however, is the much weaker relationship between the quality ratıngs and the communication variables on one hand, and the patient satisfaction scores, on the other We did find a significant $(P<005)$ correlation between patient satisfaction and panel-assessed psychosocial quality, but one of a modest magnitude $(019)$ This means that only $36 \%$ of the vanance in the quality assessments can be explaned by patients' satısfaction of the nine observed communication vanables the GP's 'shown interest', his verbal empathy and purposive probing have a sıgnificant (but equally modest) correlation with patient satisfaction We did not expect this modest relationship, because the way the satisfaction questions were formulated (see Appendix) is close to the operationalisation of many of our communication variables But the results are in line with Lebow's cautions in the use of patients' assessments [8] and the comparable results in some other studies DiMatteo found low correlations (average $r=010$ ) between physicians and patients as rating source [9], Comstock found that physician empathy correlated with patient satusfaction only weakly, while physical attention (e g eye contact) did not correlate with satisfaction at all [58], Wolraigh found the interesting result that physician's relational behaviour correlated with physician's estimate of patient satisfaction, but not with patient satisfaction as verbalized by the patient himseif [63], a result that was also found by Merkel [67] Stewart found nonsignificant correlations between patient satisfaction and several modes of patient-centered behaviour [68] Significant meaningful correlations are sometimes found in studies which use analogues instead of real patients [64], while the doctor-patient communi- cation is not measured independently from patients' satisfaction [69].

One possible explanation for this modest relationships could be, that patients are, on the whole, very satisfied with their general practitioner The range of the scores is very short In the case of some questions on the Patient Satisfaction Scale in our study the lowest score (on a 5-point scale) is the neutral one Transformed to a 100 -point-scale, as carned out by Ware and Hays in a comparative study on different satisfaction measures [70], the mean responses on the 6 items vary between 066 and 095 However, this problem is well known in patient satisfaction research A close inspection of the data of other research projects reveals that the data distribution of patient satisfaction scores is always very positively skewed Mean satısfactıon figures on that same 100 . point scale are seldom lower than 080 and often above 090 , especially the figures about satisfaction on 'humaneness' or 'affective behaviour' [56-58, 70-73] This could mean that the small differences that exist, probably say more about different answering tendencies than about differences in satisfaction There is one additional finding that underlines this supposition even doctors that only got positive quality ratıngs had patients with different satusfaction scores, and (perhaps even more important) doctors that only had negative quality scores had patsents that were very satısfied Another (methodological) explanation could be that the patient satisfaction scale while specific to communication by the doctor is non-specific as to the particular communication of the consultation, whereas the GP and psychologists' ratings are of the particular consultation and the communication skills displayed therein Some ground for this argument can be found in Verhaaks's research (using the same patient satisfaction scale), who found a relationship between patient satisfaction, patients' willingness to discuss psychosocial problems with their GP and the GP's sensitivity to psychosocial problems on the doctor's level, but not on the consultation level [34] In our study the average number of consultations per GP is too small to test this hypothesis However, as shown above, the same lack of relationship is found in studies in which specific satisfaction scales are used, so that this methodological question can hardly be a sufficient explanation for the modest relationship between patient satisfaction on the one hand and panelassessed quality of care, respectively observed communication skills on the other Nevertheless, further research into the most adequate level of analysis is recommended

\section{REFERENCES}

1 Balınt $\mathrm{M}$ The Doctor, His Patlent and the Illness Pitman Medical, London, 1957

2 Barro A R Survey and evaluation of approaches to physician performance measurement $J$ Med Assoc 48, 1051,1973

3 Inui T S, Carter W B, Kukull W A and Haigh V H Outcome-based doctor-patient interaction analysis I Comparison of techniques Med Care 20, 535, 1982

4 Carter W B, Inui T S, Kukull W A and Haigh V H Outcome-based doctor-patient interaction analysis II Identifying effective provider and patient behavior Med Care 20, 55, 1982 
5 Inus T S and Carter W B Problems and prospects for health services research on provider-patient communication Med Care 23, 21, 1985

6 Roter D. L, Hall J A and Katz N R Patientphysician communication a descriptive summary of the literature Pattent Educat Counseling 12, 99, 1988

7 Hall J A, Roter D L and Katz N R Meta-analysis of correlates of provider behavior in medical encounters Med Care 26, 657, 1988

8 Lebow J L Consumer assessments of the quality of medical care Med Care 12, 328, 1974

9 DiMatteo M R and Dinicola D D Sources of Assessment of physician performance, a study of comparative reliability and patterns of intercorrelation Med Care $19,829,1981$

10 Bensing $J \mathbf{M}$ and Sluys $E$ Evaluation of an interview training course for general practitioners $S o c$ Scl Med 20, 737, 1985

11 Bensing J $\mathbf{M}$ and Verhaak $P$ Ruimte voor de patient ("Room for the patient") Nederlands Tidschrift voor de Psychologie en haar grensgebieden 37, 19, 1982 (avallable in English )

12 Verhaak P F M Variations in the diagnosis of psychosocial disorders a general practice observation study Soc Scl Med 23, 595, 1986

13 Verhaak P F M Detection of psychological complaints by general practitioners Med Care 26, 1009 , 1988

14 White K L The Task of Medicine. Dialogue at Wickenburg The Henry J Katser Family Foundation, Calıforna, 1988.

15 Ben-Sira Z Chronic ullness, stress and coping Soc Sca Med 18, 725, 1984

16 Maes S, Spielberger C D, Defares P B and Sarason I G Topics in Health Psychology Wiley, Chicester, 1988

17 Ben-Sira $Z$ The stress-resolving component in prmary medical care Stress Med 2, 339, 1986

18 Donabedian A Explorations in Quality Assessment and Monttoring Vol II, The Criteria and Standards of Quality Health Administration Press, Ann Arbor, Michigan, 1982

19 Fine V K and Therrien M E Empathy in the doctor-patient relatıonship skill training for medical students $J$ Med Educat 52, 752, 1977

20 Dimatteo M R A social-psychological analysis of physician-patient rapport toward a science of the art of medicine $J$ Soc Issues 35, 12, 1979

21 Dimatteo $M$ R, Taranta A, Friedman H $S$ and Prince $L$ M Predictıng patient satısfaction from physician's nonverbal communication skills Med Care 18 , 376,1980

22 Ben-Sira $Z$ The function of the professional's affective behavior in client satısfaction a revised approach to social interaction theory $J$ Hlth soc Behav 17, 3, 1976

23 Ben-Sira $Z$ Affective and instrumental components in the physician-patient relationship an additional dimension of interaction theory $J$ Hlth soc Behav 21, 170 , 1980

24 Ben-Sira $Z$ Lay evaluation of medical treatment and competence-development of a model of the function of the physician's affective behavior Soc Sct Med 16, 1013,1982

25 Ben-Sira $Z$ Stress potential and esothericity of health problems the significance of the physician's affectuve behavior Med Care 20, 414, 1982

26 Korsch B $M$ and Negrete $F$ Doctor-patient communtcation Scl Am 66, 227, 1972

27 Vuon H, Aaku T, Aine E, Erkko R and Johansson $R$. Doctor-patient relationship in the light of patrents' experiences Soc $\mathrm{Scl}$ Med 6, 723, 1972

28 Van Dorp C Luisteren naar patienten de Tujdstroom, Lochem 1977
29 Friedman H S Nonverbal communication between patıents and medical practitioners $J$ soc Issues 35, 82, 1979

30 Kleın Buller $M$ and Buller D B Physicians' communication style and patient satisfaction $J$ Hlth soc Behav 28, 375, 1987

31 Royal College of General Practitioners What sort of doctor? Report from General Practice, No 23, Royal College of General Practitioners, London, 1985

32 Bensing J $M$ Watching doctors using videotapes for research purposes Conf Proc. 10th WONCA World Conference on Famuly Medicine, WONCA, Singapore, 1983

33 Grol $\mathbf{R}$ Preventieve attıtude van huisartsen, Unıversity Institute of General Practitioners, Nijmegen, Netherlands, 1981

34 Verhaak $P$ F $M$ Interpretatıe en behandeling van psychosociale klachten in de husartspraktıjk een onderzoek naar verschillen tussen husartsen Netherlands Institute for Primary Health Care, Utrecht, 1986

35 Link B, Levav J and Cohen A The primary medical care practitioner's attitudes toward psychıatry $S o c S c t$ Med 16, 1413. 1982

36 Wolffers I Hart en bloeddruk, een onderzoek in opdracht van de Consumentenbond (the Netherlands Consumer Association) Contact, Amsterdam, 1988

37 National Institute of Health, The Public and High Blood Pressure. DHEW Publication No 75 NIH, Bethesda, Maryland, 1973

38 Jenkıns C D Recent evidence supportıng psychological and social risk factors for coronary disease $\mathrm{New}^{\prime} \mathrm{Engl}$ $J$ Med 294, 987, 1976

39 Gallagher J E, Yarnell J W and Butland B Type A behaviour and prevalent heart disease in the Caerphilly Study increase in nsk or symptom reporting? $J$ Epldem community Hlth 42, 226, 1988

40 Lindgarde $F$, Furu $M$ and Ljung B-O A longitudinal study on the significance of environmental and individual factors associated with the development of essential hypertension $J$ Eptdem community Hlth 41, 220. 1987

41 Bloom J R and Monterossa S Hypertension labeling and sense of well-being $\mathrm{Am} J \mathrm{Publ}$ Hlth 71, 1228, 1981

42 Royal College of General Practitioners, Prevention of Arterial Disease in General Practice, Report from General Practice, No 19 RCGP, London, 1981

43 Office of Population Censuses and Surveys, Morbidity statistics from General Practice, Second National Study 1971-1972, Studies on Medical and Population Subjects, No 26 HMSO, London, 1979

44 Rogers C R Chent-Centered Therapy Houghton, Miffin, Boston, 1951

45 Davis $M S$ Variations in patients' complance with doctors' advice an empincal analysis of patterns of communication Am J Publ Hlth 58, 274, 1968

46 Francis $V$, Korsch B $M$ and Morris $M J$ Gaps in doctor-patient communication New Engl J Med 280, 535,1969

47 Gask L, Goldberg D, Lesser A L and Millar T Improving the psychiatric skılls of the general practice trainee an evaluation of a group training course $\mathrm{Med}$ Educat 4, 22, 132, 1988

48 Gask L McGrath G, Goldberg D and Millar T Improving the psychiatric skills of established general practitioners evaluation of group teaching Med Educal 2, 21, 362, 1987

49 Like $R$ and Zyzanskı S J Patient satısfactıon with the clinical encounter social psychological determinants Soc Scl Med 24, 351, 1987

50 Sluys E $M$ and van der Leden J Methodisch werken de ontwikkelingen sinds 1976 Huisarts en Wetenschap 31, Suppl 3-7, 1988 
51 Byrne $P$ S and Long, B E L Doctors Talking to Patlents. Her Majesty's Stationary Office, London, 1976

52 Barsky A J, Kazıs L E and Freıden R B Evaluatung the interview in primary care medicine $\mathrm{Soc} S \mathrm{St} \mathrm{Med}$ 14a, 653, 1980

53 Speedling $E \mathrm{~J}$ and Rose D N Buiding an effective doctor-patient relationship from patient satisfaction to patient participation Soc Scl Med 24, 351, 1985

54 Cassee E Naar de Dokter ("going to see the doctor") Boom, Meppel, 1973

55 Zastowny $\mathbf{T} \mathbf{R}$, Roghman $\mathbf{K} \mathbf{J}$ and Hengst $A$ Satisfaction with medical care replications and theoretic reevaluation Med Care 21, 294, 1983

56 Putnam S M, Stiles W B, Jacob M C and James S A Patient exposition and physician explanation in initial medical interviews and outcomes of clinic visits Med Care 23, 74, 1985

57 Zyzanskı S J, Hulka B S and Casel J C Scale for the measurement of "satisfaction" with medical care modifications in content, format and sconing Med Care $12,611,1974$

58 Comstock L M, Hooper E M, Goodwin J $M$ and Goodwin J S Physician behaviors that correlate with patient satisfaction $J$ Med Educat 57, 105, 1982

59 Ware $J$ E and Snyder $M K$ Dimensions of patient attitudes regarding doctors and medical care services Med Care 13, 669, 1975

60 Robcrts J G and Tugwell $P$ Comparison of questionnaires determining patient satusfaction with medical care Hith Services Res 22, 637, 1987

61 Hornsby J L and Payne E A model for communication skills development for family practice residents J family Practice 8, 71, 1979

62 Fitzpatrick R and Hopkins A Problems in the conceptual framework of patient satisfaction research an empincal exploration Sociol Hlth Illness 5, 297, 1983

63 Wolraigh $M$ L, Albanese M, Stone G, Nesbitt D, Thomson E, Shymansky J, Bartley J and Hanson J Medical communication behavior system An interactional analysis system for medical interactions $\mathrm{Med}$ Care 24, 891, 1986

64 Roter D L, Hall J A and Katz N R Relations between physicians' behaviors and analogue patients satisfaction, recall and impressions Med Care 25, 437, 1987

65 Roter D Patient question asking in physician-patient interaction Hlth Psychol 3, 392, 1985

66 Davis K Power under the Microscope Foris Publications, Dordrecht, 1988

67 Merkel W T Physician perception of patient satısfaction-do doctors know which patuents are satisfied? Med Care 22, 453,1984

68 Stewart M A What is a succesful doctor-patient interview? A study of interactions and outcomes $S o c$ Sct Med 19, 167, 1984

69 Willson $P$ and McNamara J R How perceptions of a simulated physician-patient interaction influence intended satisfaction and compliance $S_{o c} S_{C l} \mathrm{Med}$ 16, 1699, 1982

70 Ware J E and Hays R D Methods for measuring patient satisfaction with specific medical encounters Med Care 26, 393, 1988

71 Stules W B, Putnam S. M, Wolf M H and James S A Interaction exchange structure and patient satısfaction with medical interviews Med Care 17, 667, 1979

72 Weinberger $M$, Greene $J$ Y and Mamlin J J The impact of clinical encounter events on patient and physician satisfaction $S o c$ Sct Med 15e, 239, 1981

73 Woolley $F R$, Kane $R L$, Hughes $C C$ and Wright D D The effects of doctor-patient communication on satisfaction and outcome of care $S_{o c} S_{c l}$ Med 12, 123, 1978

74 Locker D and Dunt D Theoretical and methodological issues in sociological studies of consumer satisfaction with medical care Soc Scl Med 12, 283, 1978

\section{APPENDIX}

Items of the Pattent Satisfaction Scale (5-Point Scale)

1 My doctor knows exactly what is wrong

2 My doctor keeps his patients at a distance(-)

3 My doctor is interested in me as a person

4 My doctor is good at handling problems

5 My doctor talks about non-medical problems as wel]

6 My doctor allows enough tume for me 